\title{
Presence and Location of Adrenergic Nerve Endings in the Dental Pulps of Mouse Molars
}

\author{
JAMES K. AVERY, CHARLES F. COX, AND DANIEL J. CHIEGO, JR. \\ Laboratory of Oral Histology, Dental Research Institute, The University of Michigan, \\ Ann Arbor, Michigan 48109
}

\begin{abstract}
In all, 30 adult (45-day-old) Swiss Webster mice were used for light and electron microscopic examination of the presence, number, and location of adrenergic endings in the first molar teeth. Prior to sacrifice, 10 animals received i.p. injections at $8,6,4$, and 2 hours of $0.5 \mathrm{cc}$ of $20 \mathrm{mg} / \mathrm{kg}$ solution of 5 . hydroxydopamine (5-OH-DA) as a label for adrenergic endings. The animals were then anesthetized, perfused with Karnovsky's fixative, and the teeth were postfixed in Osmic acid, decalcified, embedded in methacrylate, and serialsectioned. The sections were surveyed by light microscopy, and the number and location of nerve endings containing the reduced 5-OH-DA were recorded. Ten control mice were injected with the vehicle solution and prepared in the same manner. A third series of mice were given a single injection of 5-OH-DA, sacrificed, and prepared for ultrastructural study. The molar pulps were divided into four areas to facilitate examination: pulp horns, coronal pulp, bifurcation area, and root pulp. These four areas were further divided into three zones: odontogenic, vascular-related, and nonvascular-associated. The location and number of endings were evaluated, and an average of approximately 70 endings containing the 5-OH-DA were found in each tooth using light microscopy. These represented $35.5 \pm 5.2$ in the pulp horns; $26.1 \pm 2.4$ in the central coronal; $5.4 \pm 0.7$ in the bifurcation, and $5.6 \pm 0.9$ in the root pulp per tooth. Vascular related endings were found in greatest number, the odontogenic zone next, and free endings least. Verification of location of 5-OH-DA by ultrastructural analysis revealed the false transmitter in vesiculated endings in the four areas and zones of the pulp.
\end{abstract}

The presence of small unmyelinated nerves in the region of the odontoblasts and within dentinal tubules has been described in ultrastructural studies by several investigators, Johansen ('67), Arwill ('67), and Frank ('68a, b). These intradentinal nerve fibers contained neurotubules, mitochondria, and small vesicles. Corpron and Avery ('73) traced axons as far as $80 \mu \mathrm{m}$ into the dentinal tubules, although no nerves were observed in peripheral dentin or near the dentino-enamel junction, as in agreement with Tsatsas and Frank ('72). Nerve endings found among the odontoblasts and within the dentinal tubules appeared as membrane-bound structures filled with vesicles and a few mitochondria (Avery, '75). The appearance of these nerve endings in cross section was oval or round, although when viewed in long axis, the terminals appeared elongated with alternating dilated and constricted parts. The majority of these nerve endings were found closely associated with the cell bodies of the odontoblasts, some indenting the plasma membrane of the cells or interdigitating with the cytoplasm of the processes within the dentinal tubules. The free axons or the nerve endings were separated from the odontoblasts or their intratubular processes by a cleft of approximately $200 \AA$. Richardson ('66) and Hand ('72) utilized potassium permanganate fixation and were able to discern two types of vesiculated nerve endings, one type containing granular vesicles, the other agranular. They concluded the granular vesicles were adrenergic in nature and the agranular ones were cholinergic. Examination of the odontogenic zone by this technique re-

'This research was supported by Grant DE 01604 from The National Institute for Dental Research, National Institutes of Health. Bethesda. Md.

Received November 12, 1979; accepted April 23, 1980 
vealed a few terminals containing dense core granular vesicles $(300-700 \AA$ in diameter) and other more numerous endings with agranular vesicles (Avery and Cox, '77). According to Richardson ('66), the potassium permanganate improves the preservation of the dense granular cores over that of glutaraldehyde and $\mathrm{OsO}_{4}$, the typically used fixative described by Tranzer and Thoenen ('67). According to Hökfelt and Johnson ('68), an electron-dense precipitate of manganese dioxide is formed when noradrenaline reduces permanganate. Using a histochemical fluorescence method, Anneroth and Norberg ('68), Pohto and Antila ('68), and Pohto ('72) confirmed the presence of adrenergic nerves along blood vessels in pulps of teeth of higher mammals and humans. Larsson and Linde (71), using the method of Falk et al. ('62), observed the presence of sympathetic nerves in tooth pulps. They administered a monoamine oxidase inhibitor and noradrenaline, which caused an increase in fluorescence, while cervical sympathectomy abolished fluorescence; thus, they postulated a possible adrenergic regulation of blood flow. Nakano et al. ('70) and Pohto et al. (72) quantitated noradrenaline in dental pulps, which confirmed the adrenergic nature of autonomic nerve plexuses earlier indicated by histochemical methods.

Nerve resection studies have also been used to clarify the identity of nerves in the pulps and dentinal tubules of mice (Corpron et al., '72). Inferior alveolar nerve (IAN) resection resulted in the degeneration of most of the nerve endings in the dentinal tubules and apical region of the odontoblast. Arwill et al. (73) also noted loss of intradentinal nerves after IAN resection; however, resection of the cervical sympathetic ganglion (SCG) did not eliminate the number of intratubular neural structures. Similar studies by Feher et al. ('77) revealed that after transection of the IAN, all myelinated and some unmyelinated nerve fibers degenerated. A further nerve resection study in mice teeth revealed that a few nerve endings still persisted after both IAN and SCG resection. This was found to be due to the presence of accessory nerves that supply the molar teeth (Yax et al., '77). With these findings of accessory nerve branches to the mandibular teeth, it was decided to undertake a thorough study of the nerve supply to teeth. One method used was horseradish peroxidase (HRP), which is noted to migrate both retrograde and anterograde without crossing a synapse. Studies using HRP revealed a transme- dian innervation of both the incisor and canine teeth, but not the posterior premolars and molars (Cox et al., '77; Chiego et al., '80). In regard to the latter, HRP was found in the ipsilateral $\mathrm{V}$ ganglia, and no label in the contralateral ganglia. With the knowledge that teeth have both a sympathetic and sensory nerve supply, the present investigation was carried out in order to determine the approximate number and the geographic distribution of adrenergic nerve endings within the first mandibular molar teeth of mice. The method of choice for visualization of sympathetic terminals was that of 5-hydroxydopamine (Tranzer and Thoenen, '67). It is known that endogenous, naturally occurring biogenic amines can be displaced by $5-\mathrm{OH}-\mathrm{DA}(3,4,5$ -Trihydroxy-phenyl-ethylamine). This substance is, therefore, a specific marker for adrenergic terminals in the peripheral nervous system (Tranzer and Thoenen, '67). Pretreatment by intraperitoneal injection of this false neurotransmitter prior to sacrifice of the animal assures its accumulation at all adrenergic endings. Again, this substance can be preciptated by means of glutaraldehyde, and this substance is believed, in turn, to reduce the oxmium tetroxide to an electron-dense material that can be visualized at either the light or electron microscopic levels. Moreover, since the 5-OH-DA localizes only in an adrenergic terminal, the method allows precise localization of these endings.

\section{MATERIALS AND METHODS}

\section{Light microscopic procedures}

A series of 20 Swiss Webster mice were used in this study. The animals were injected four times at 2-hour intervals, for a total of 8 hours before sacrifice with 5-OH-DA-1. Each mouse was injected i.p. with $0.5 \mathrm{cc}$ of $20 \mathrm{mg} / \mathrm{kg}$ solution of 5-OH-DA. A solution was prepared by dissolving 5-OH-DA crystals in sterile lactated Ringer's with $0.2 \mathrm{mg}$ ascorbic acid added to prevent oxidation. This solution was prepared immediately before use and sonicated for 2 minutes at $22^{\circ} \mathrm{C}$ at $50 \mu \mathrm{A}$. A series of 10 control animals was injected with a $0.5 \mathrm{cc}$ of lactated Ringer's solution containing $0.2 \mathrm{mg}$ of ascorbic acid. At completion of the time interval, the mice were anesthetized with a $0.5 \mathrm{cc}(3.5 \%)$ i.m. injection of chloral hydrate. The animals were then sacrificed by left ven-

\footnotetext{
15-Hydroxydopamine $(3,4,5$,-Trihydroxy-phenyl-ethylamine) Lot 699-A
} 
tricular perfusion using Karnovsky's (GTA$\mathrm{PBF}$ ) fixative (25 $\mathrm{ml}$ of $8 \%$ paraformaldehyde, $5 \mathrm{ml}$ of $50 \%$ glutaraldehyde diluted to $50 \mathrm{ml}$ with phosphate buffer having a $\mathrm{pH}$ of 7.4). Approximately $10 \mathrm{cc}$ of fixative was injected into the left ventricle while cutting the right auricle for relief of intravascular pressure. The first mandibular molars were removed and postfixed in GTA-PBF for 1 hour. After precipitation of the false neurotransmitter with glutaraldehyde, all teeth were then washed in buffer and postfixed in a buffered $2 \%$ osmium tetroxide for 2 hours. The latter is reduced by the 5-OH-DA to produce a dense material. The teeth were then decalcified in isotonic neutral disodium EDTA at room temperature, with constant agitation on a shaker bath for 1 week, changing the EDTA every day. Following decalcification, the teeth were dehydrated in an ascending ethyl alcohol series. The teeth were then infiltrated in a graded series of butoxyethanol glycol methacrylate $^{2}$ minus accelerator for 4 days. Each tooth was then oriented in the saggital plane for embedding and sectioning. The teeth were serially sectioned at $4.5 \mu \mathrm{m}$ and each slide counterstained with a modified Halmi stain (Fullmer, '59) for 1 minute. The serial sections were each scanned under high magnification for the 5-OH-DA dense stained endings, characterized, and recorded using a camera lucida. Tracings of each pulp outlined and the number and location of the endings were then recorded. To facilitate geographic location of nerve endings, the pulp organ was divided into four anatomically defineable areas: pulp horns, central coronal, bifurcation, and root canals. To further distinguish locations common to each of these areas, several zones were then defined: (1) odontogenic or near the dentin formation front; (2) blood vessel-associated, and (3) lying free, or seemingly non-vascularrelated. With these subdivisions, locations could be recorded effectively. In Figures 1 and 2 the four areas and three zones of the pulp are shown. The black areas in Figure 1 indicate the location of the larger vascular channels of the mouse pulp. These are included to show both the size and location of the major vessels. Many similar vessels appear through- out the coronal and root pulp.

\section{Electron microscopic procedures}

The teeth used in this portion of the study were obtained from ten Swiss Webster mice. These mice were injected i.p. with $33 \mathrm{mg} / \mathrm{kg}$ body weight of a 5-OH-DA solution (Avery and Cox, '77). This dosage rate was found to be an effective label for one injection 12 hours prior to sacrifice. The teeth were removed, split, postfixed, and decalcified as above, dehydrated with alcohols to propylene oxide, and embedded in Epon. Thick sections of $1 \mu \mathrm{m}$ were then serially taken and placed on gelatinized slides. Appropriate areas for ultrastructural analysis were chosen from each of the four areas and mesas placed for ultrathin sectioning. Sections were placed on copper grids and viewed on a Zeiss EM-9S2 at primary magnifications ranging from $4,000 \mathrm{X}$ to $9,000 \mathrm{X}$ at $60 \mathrm{KV}$.

\section{RESULTS}

\section{Light microscopic observations}

Pretreatment with the false sympathetic neurotransmitter 5-OH-DA leads to an accumulation of osmiophilic substance within the vesicles of adrenergic terminals. This substance is believed to be precipitated by glutaraldehyde and then reduces the osmic acid to a dense constituent of the vesicles within the endings. As seen in Figure 3 by light microscopy, the ending is characterized by blackstaining granules of various sizes that are localized within the adrenergic ending. Each ending was identified and counted only if it fit the criteria of a stained and localized precipitate. Of the ten teeth utilized for this study, two were eliminated because of lack of complete serial sections. The pulp horns consistently showed the highest percentage of 5-hydroxydopamine cytochemically labeled terminals, with a total of 284 counted, or $48.9 \%$ of the 581 endings observed. The pulp horn compartment was divided into odontogenic zone, free-lying zone, and vascular-related zone, as seen graphically in the diagram (Fig. 4). Within the pulp horn area, the vascular-related consisted of a total of $121 \pm 9.6$ labeled end-
D Dentin

N Nucleus

o Odontoblast Layer
Abbreviations

P Pulp

PVC Perivascular Cell

RBC Red Blood Cell

${ }^{2}$ JB-4 Embedding Kit, Polysciences Inc., Paul Valley Industrial Park, Warrington, PA 18975. 

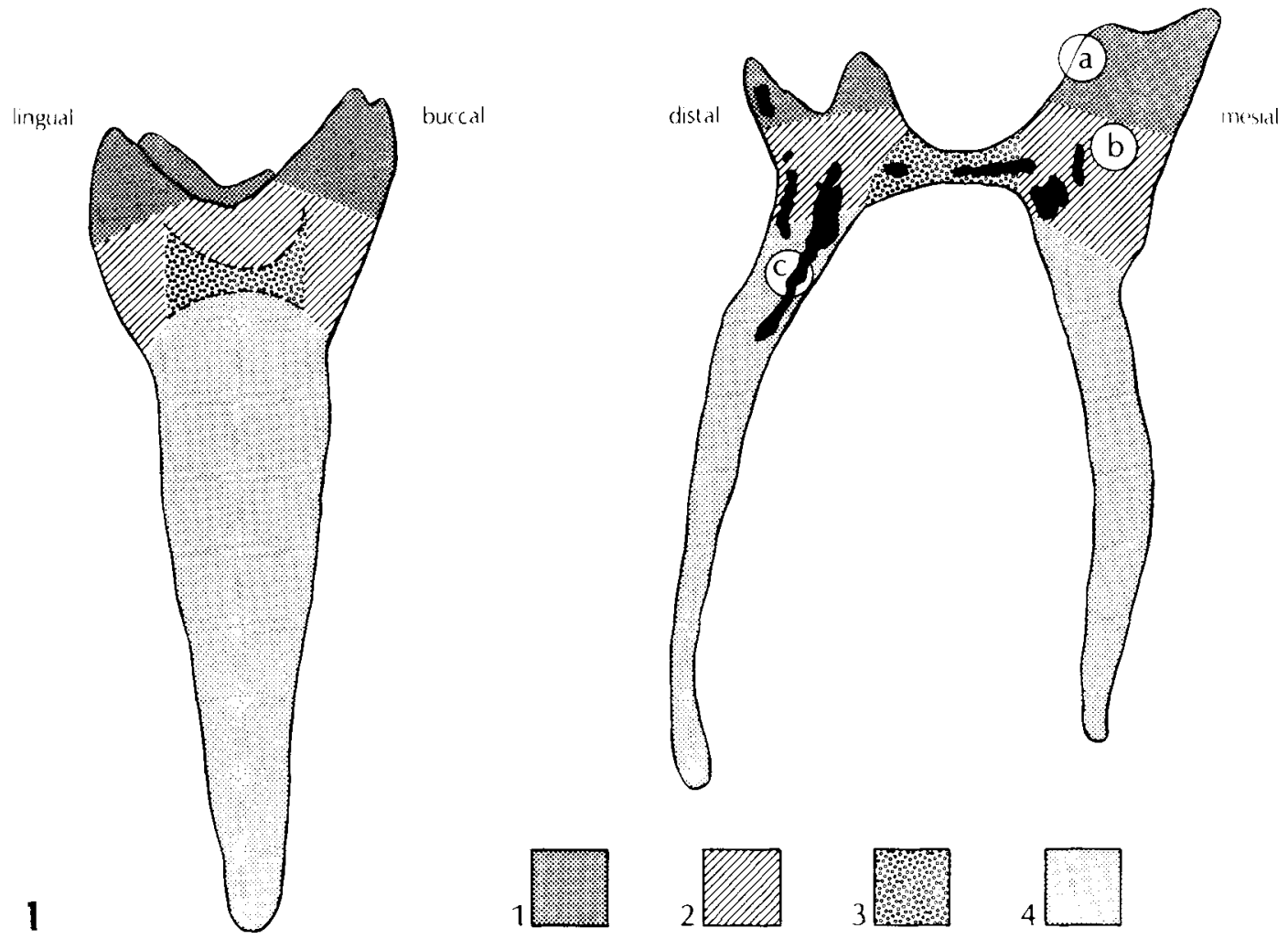

Fig. 1. A diagram of a reconstructed first mandibular molar on the left, and a camera lucida tracing on the right. Each tooth was divided into four areas for examination: (1) pulp horn, (2) central coronal, (3) bifurcation, and (4) root pulp. Each of these areas was further characterized into: (a) odontogenic zone, (b) free-lying endings not associated with blood vessels, and (c) endings associated with blood vessels. The black areas seen within the mesial-distal profile represent vascular channels.

ings. The free-lying terminals consisted of 70 \pm 2.3 , which were found upon evaluation of serial sections not to be lying closely adjacent to vessels. They may, however, be related to the vessels that do lie within $10-15 \mu$ from them. The odontogenic zone of the pulp horn contained a total of $93 \pm 5.1$ endings. These endings varied in proximity to the odontoblasts and the numerous capillaries and precapillaries located among the odontoblasts (Fig. 5).

The central coronal pulp contained the second highest number of 5-OH-DA-labeled endings, with a total number of 209 counted, or $36 \%$ of all 581 endings counted. Within this area the vascular-related endings comprised the greatest number, with $78 \pm 1.9$ counted. The free-lying ending values were slightly lower at $73 \pm 3.1$, and the least number of endings were found in the odontogenic zone at $56 \pm 2.4$. Both the bifurcation and root pulp areas contained approximately equal numbers of labeled endings within the three zones. The bifurcation area contained 43 endings, with $15 \pm 1.7$ observed in the odontogenic zone, 14 \pm 0.8 free endings, and $14 \pm 0.6$ associated with blood vessels. There were 45 endings observed in the root pulp area, with $14 \pm 0.5$ free in the pulp and $17 \pm 0.8$ endings related to blood vessels (Table 1 ).

Overall there were approximately $705-\mathrm{OH}$ DA-labeled nerve endings counted within each mouse molar pulp. The highest concentration of endings was found in the pulp horn area, followed by the central coronal area, and the lesser numbers in the bifurcation and root pulp areas. In three of the four areas - pulp horn, central coronal, and root pulp--the vascular-related endings were the most numerous.

The size of the endings, estimated from the total granular profile dimensions, ranged from 8 to $14 \mu \mathrm{m}$ in the odontogenic region of the pulp horn, and from 3 to $10 \mu \mathrm{m}$ in the central 

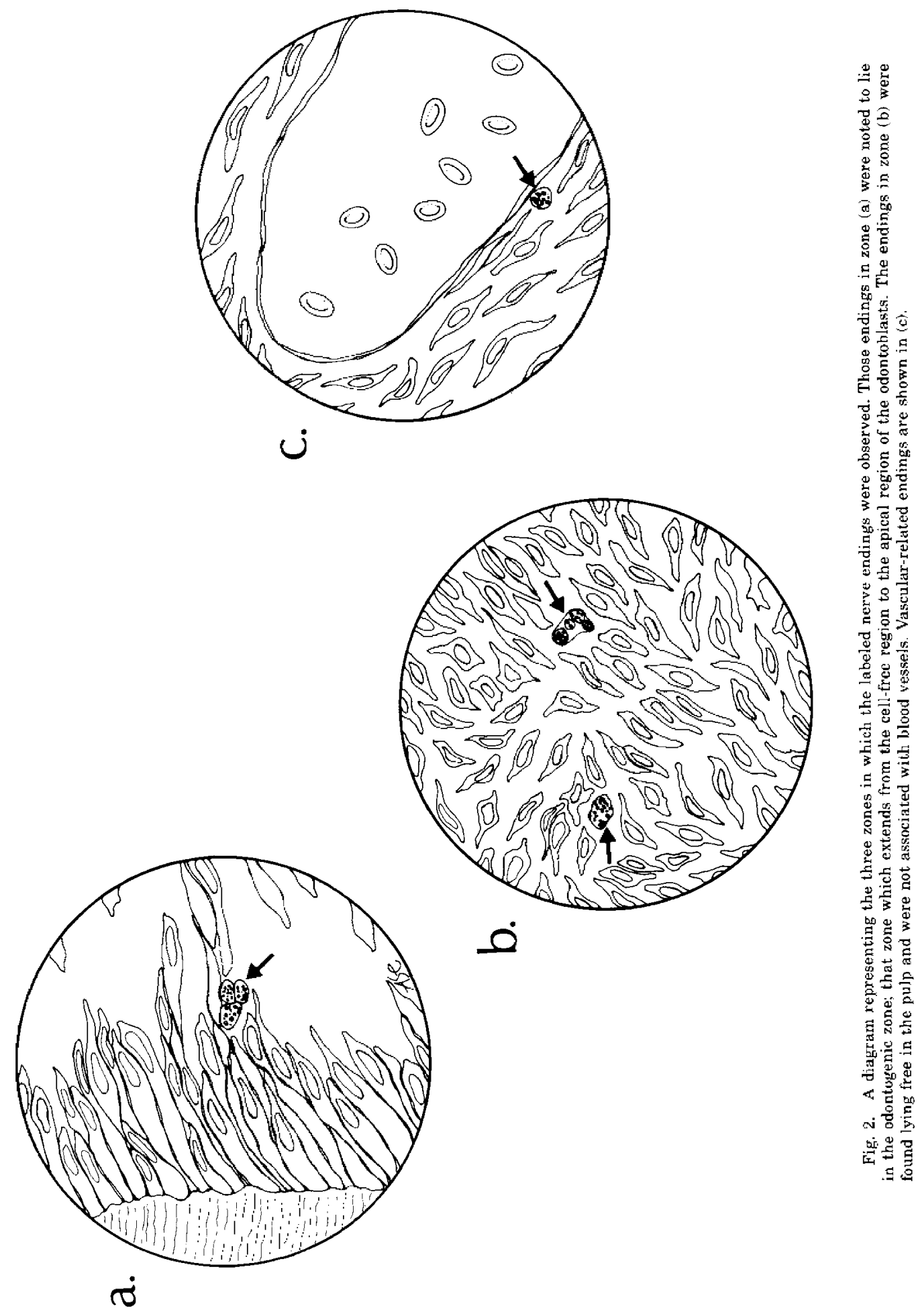


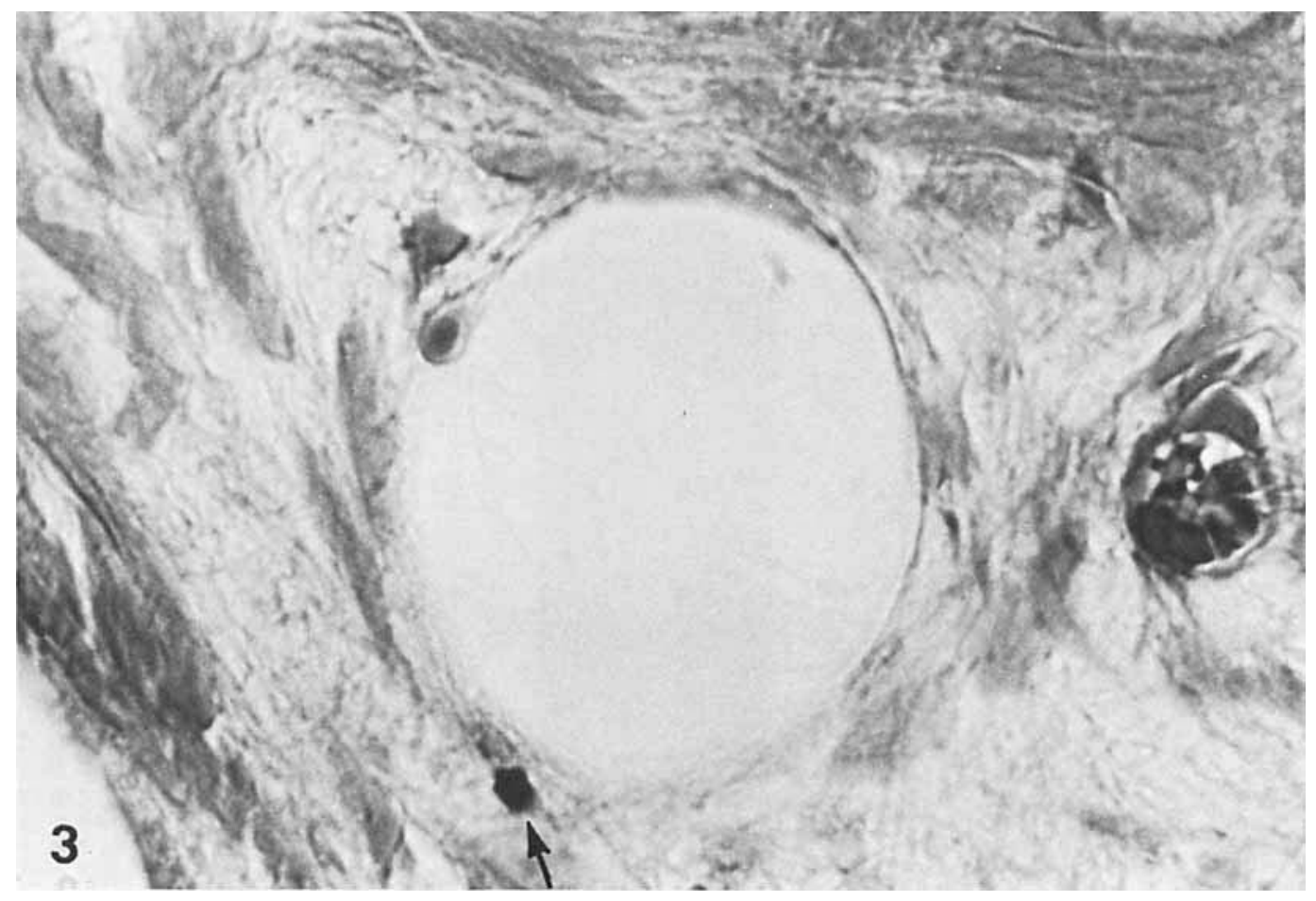

Fig. 3. A light micrograph of a 5-hydroxydopamine-labeled nerve ending adjacent to a blood vessel of the central pulp. The ending is composed of a cluster of black-stained granules (arrow). Halmi stain. X 400 .

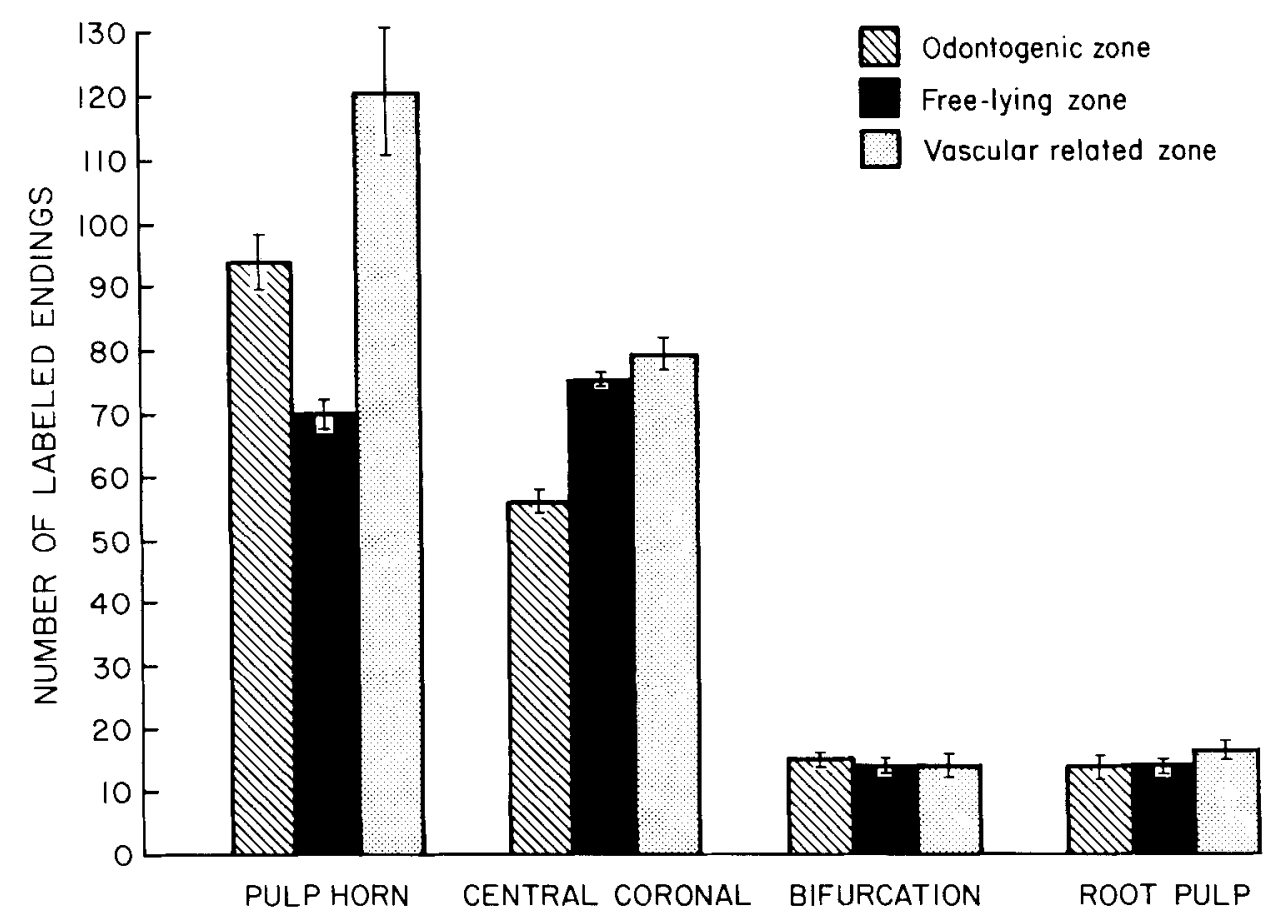

Fig. 4. A histogram representative of the total numbers and distributions of labeled adrenergic endings located in the four areas and three zones of mice first molar teeth after pretreatment with 5-OH-DA. 
TABLE 1. Total $\pm S D^{*}$ 5-OH-DA-labeled adrenergic nerve endings located in the mouse first molar

\begin{tabular}{|c|c|c|c|c|}
\hline \multirow[b]{2}{*}{$\begin{array}{c}\text { Zones } \\
\text { (Locations common to areas } \\
1-4)\end{array}$} & \multicolumn{4}{|c|}{ Areas } \\
\hline & $\begin{array}{c}1 \\
\text { Pulp horn }\end{array}$ & $\begin{array}{c}2 \\
\text { Central } \\
\text { contral }\end{array}$ & $\begin{array}{c}3 \\
\text { Bifurcation }\end{array}$ & $\begin{array}{l}\quad 4 \\
\text { Root pulp }\end{array}$ \\
\hline Odontogenic & $\mathrm{n}=93 \pm 5.1$ & $\mathrm{n}=56 \pm 2.4$ & $\mathrm{n}=15 \pm 1.3$ & $\mathrm{n}=14 \pm 0.9$ \\
\hline Free endings & $n=70 \pm 2.3$ & $\mathrm{n}=75 \pm 1.1$ & $n=14 \pm 0.8$ & $\mathrm{n}=14 \pm 0.5$ \\
\hline Vascular-related & $\mathrm{n}=121 \pm 9.6$ & $\mathrm{n}=78 \pm 1.9$ & $\mathrm{n}=14 \pm 0.6$ & $\mathbf{n}=17 \pm 0.8$ \\
\hline Totals ( 8 teeth) & $N=284$ & $N=209$ & $N=43$ & $N=45$ \\
\hline $\begin{array}{l}\% \text { of total adrenergic nerve } \\
\text { endings observed per area, } \\
\text { including three zones }\end{array}$ & $48.9 \%$ & $36 \%$ & $7.4 \%$ & $7.7 \%$ \\
\hline $\begin{array}{l}\text { * Mean } \pm \text { SD of total } \\
\text { adrenergic nerve endings } \\
\text { observed per area, } \\
\text { including all three zones }\end{array}$ & $35.5 \pm 5.2$ & $26.1 \pm 2.4$ & $5.4 \pm 0.7$ & $5.6 \pm 0.9$ \\
\hline
\end{tabular}

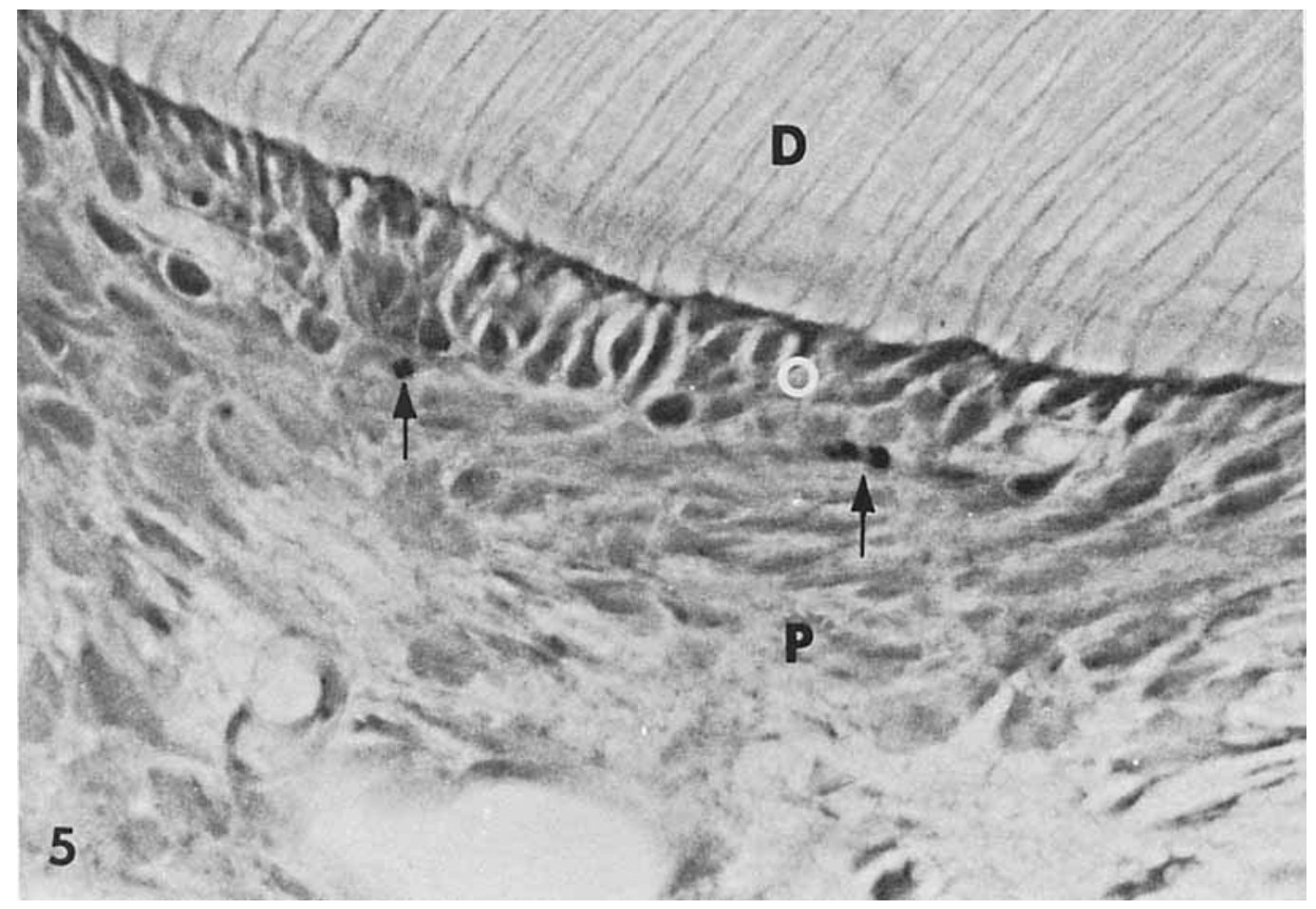

Fig. 5. A light micrograph of several 5-OH-DA-labeled nerve endings in the odontogenic zone (O); above is seen dentin (D), and below, pulp (P) and endings (arrows). Halmi stain. X 160. 


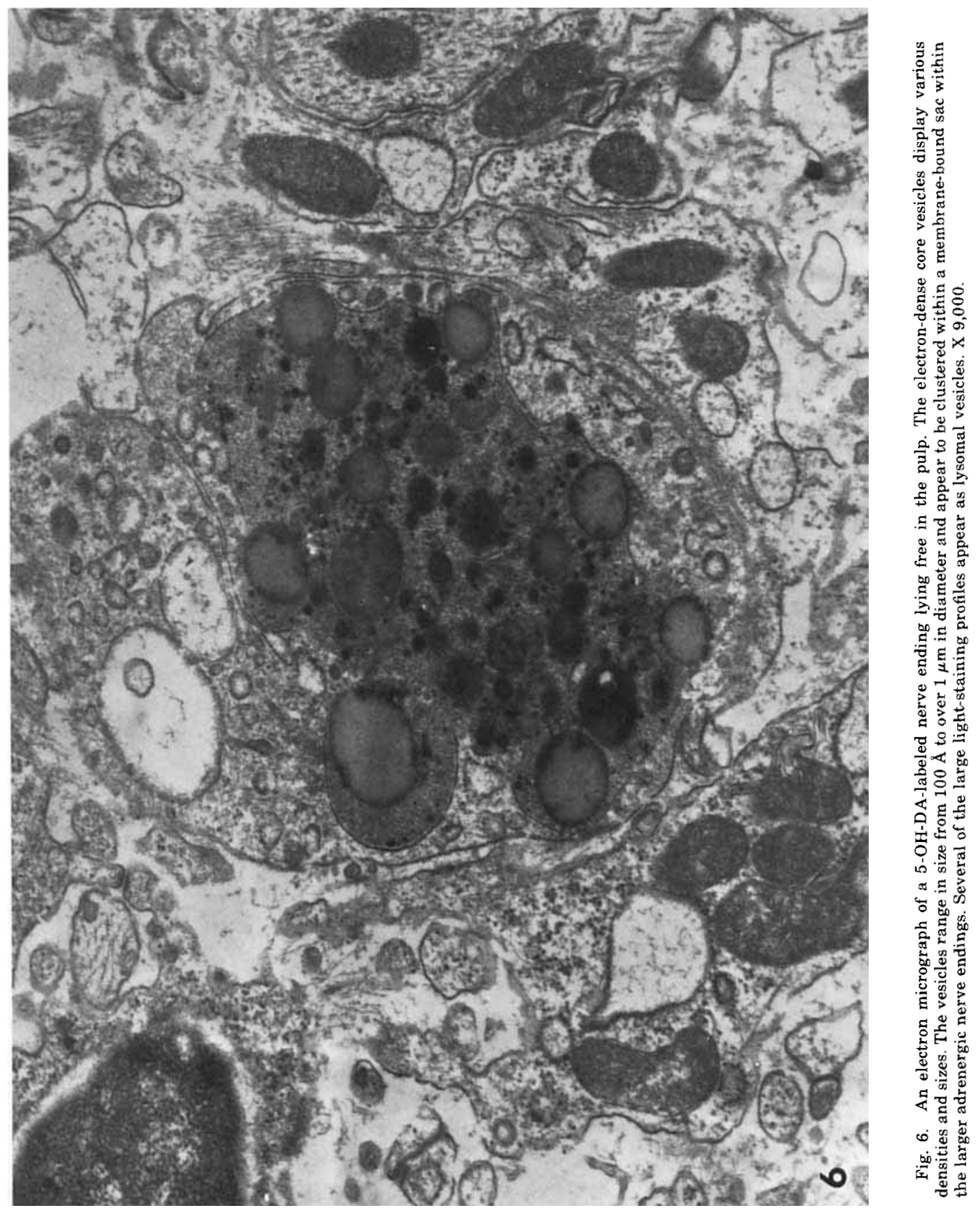


pulp area. Occasionally, smaller granular profiles ranging from 2.5 to $5 \mu \mathrm{m}$ were associated with the blood vessels.

\section{Electron microscopic observations}

Visualization of the 5-OH-DA electrondense vesicles revealed a range in size of the electron-dense vesicles. The majority of the vesicles appeared to be small, ranging from $100-400 \AA$ in size, while a larger series measured 500-1,500 $\AA$ (Fig. 5). The small vesicles appear to be notably electron-dense and granulated, while the larger vesicles appear more electron-lucent (Fig. 7). It is also apparent that all of the vesicles in each terminal are not stained. As can be observed in Figure 8, the 5-OH-DA-labeled endings are in the vacinity of non-labeled endings, which bear no dopamine. It is theorized that these are cholinergic. The majority of the adrenergic terminals are near blood vessel walls. Since there is a minimal amount of muscle cells on these vessels, it may be the pericapillary cells, as seen in Figure 8 , that respond to the sympathetic stimuli (Tranzer and Thoenen '67).

\section{DISCUSSION}

The early characterization of small myelinated and non-myelinated nerves and nerve terminals in the dental pulp, especially in relationship to the odontogenic region, has been studied using various methods and animal models, adding perturbations to an already complex problem. The recent studies of Corpron and Avery ('73), using electron microscopy, has alleviated much of the confusion regarding the location of nerve endings and their relationship to the odontoblast and its process in the dentinal tubules. The functional significance of the various terminals in this location remains equivocal, however.

Numerous investigators (Chiba '73; Tranzer et al., '69; Mazzuca and Poulain, '71; Prentice

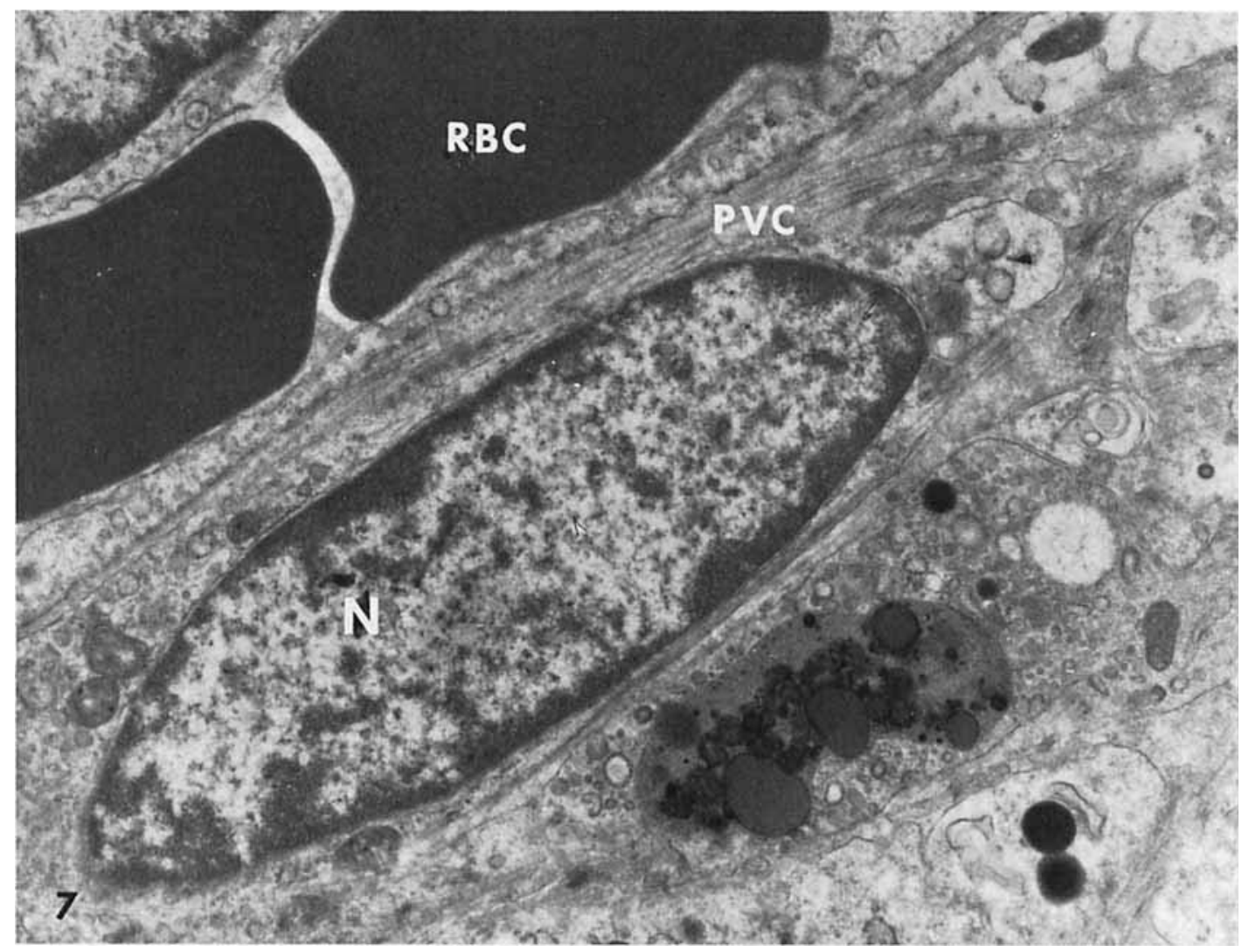

Fig. 7. An electron micrograph of a 5-OH-DA-labeled ending juxtaposed to a perivascular cell (PVC) adjacent to a capillary in the central dental pulp. Red blood cell (RBC) and small, electron-dense vesicles are present along with larger, less dense ones. The cluster of electron-dense vesicles is enclosed within the membrane of the ending. $X 4,900$. 


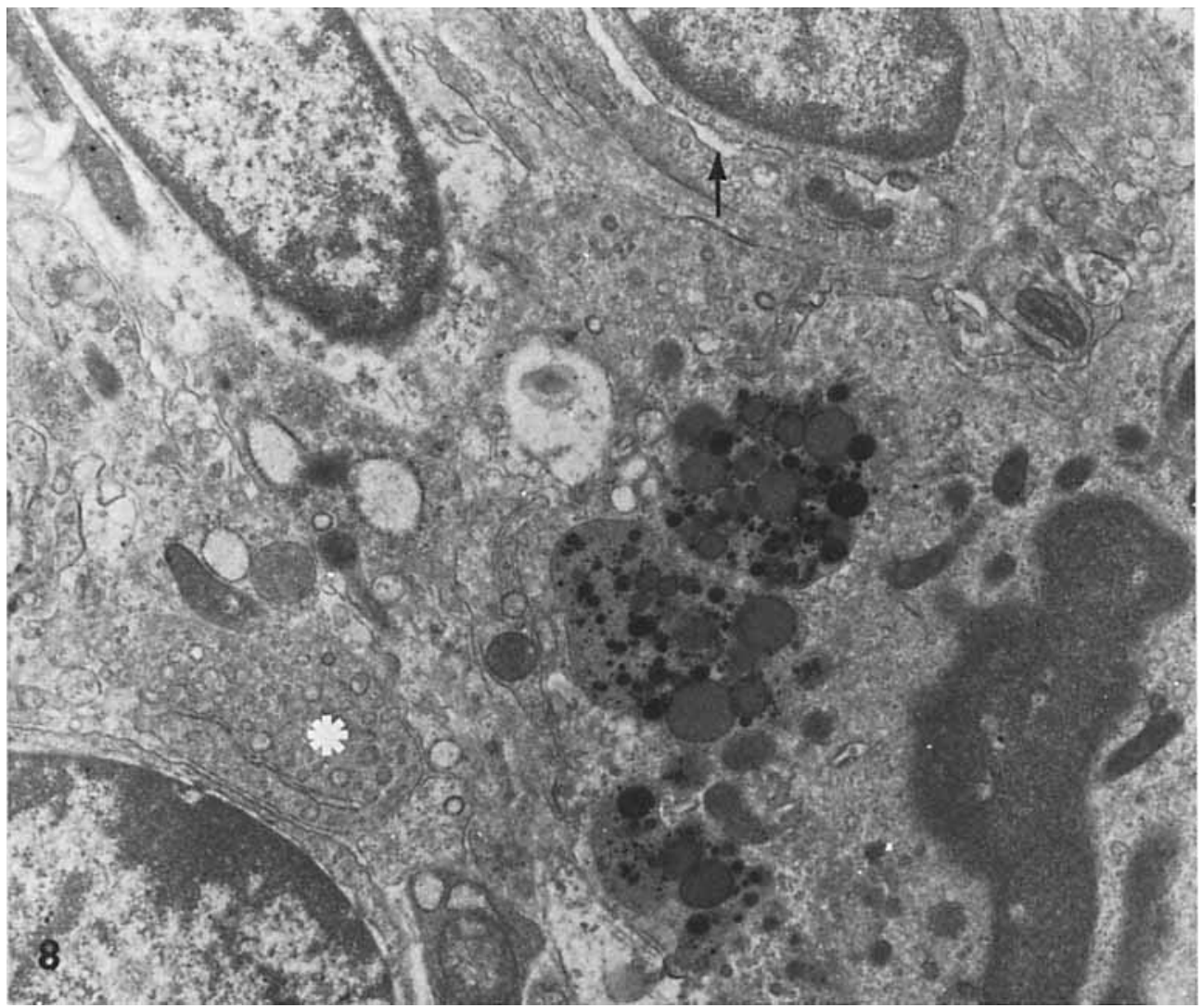

Fig. 8. Multilobulated accumulation of 5-OH-DA located near a nonlabeled cholinergic ending $\left(^{*}\right)$ in the central pulp region. The lumen of a capillary is seen at the arrow. $\mathrm{X} 4,900$.

and Wood, '74; Tranzer and Thoenen, '67; Richards and Tranzer, '70; Avery '79) have reported that 5-OH-DA specifically labels adrenergic (Catecholamine-containing) nerves and nerve terminals. The present study also corroborates the finding of adrenergic nerve fibers in the pulps using histochemical fluorescence by Pohto and Antila ('68) and Photo et al. ('72); the biochemical techniques of Nakano et al. (70) in the dental pulp, and the ultrastructural localization and characterization of adrenergic terminals by Avery ('75), using the permanganate method of Richardson ('66) in the tooth pulp.

This paper reports the presence of two populations of 5-OH-DA containing vesicles located within the adrenergic nerve endings. The small ones ranged from 100-400 $\AA$, and the larger ones measured $500-1,500 \AA$. Although several investigators (Bodian, '66; Sotelo, '71) have reported vesicles ranging from $100 \AA-4,000 \AA$, the majority favor a range of
$100 \AA-1,200 \AA$, which is consistent with our findings (Chiba, '73; Tranzer et al., '69; Ibata et al., '74). All of these investigators have found both small and large stained vesicles. The lack of density of the larger vesicles is of interest. Chiba (73) reported a range of densities from I to IV after varying concentrations from 50 to $500 \mathrm{mg} / \mathrm{kg}$ of body weight. He also found fewer vesicles labeled after injection of less than $100 \mathrm{mg} / \mathrm{kg}$. It is probable that the single injection of $33 \mathrm{mg} / \mathrm{kg}$ in the present study accounts for the lucency of the larger vesicles. It also can be observed that all vesicles in an ending were not labeled. It is also possible that the decalcitive EDTA may alter the staining properties.

The results of the present study have shown that the highest percentage ( $48.9 \%$ ) of labeled nerve endings was found in the pulp horn, and that the largest proportion of those endings both in the pulp horn and elsewhere were associated with the blood vessels. This obser- 
vation substantiates previous observations by Pohto and Antila ('68) in human 3rd molar pulps. They found terminals associated with arterioles and thin-walled venules in the pulp horn region. Expression of the findings in the manner we have presented them may be misleading, as all terminals in pulps may in some way be vascular-related. Those among the odontoblasts are near the capillaries and precapillaries that course around these cells. This distribution in the pulp horns, however, does not relate to the location of any of the larger arteries and veins of the pulp, which are more centrally located in the coronal and root pulp. The root pulp had only 17 vessel-related terminals, as compared to 78 in the central coronal area and 121 in the pulp horn area.

Among the several possibilities that exist for the presence of adrenergic endings in the pulp is control of the vasculature in response to trauma such as attrition or dental caries, which may result in pulpal inflammation and hyperemia. Since the dental pulp is confined in a nondistensible covering of dentin, it is of paramount importance that the blood supply be strictly regulated for control of extracellular and intracellular fluids; for if this were not the case, minor inflammatory changes in the pulp could result in widespread ischemic necrosis and, subsequently, death of this organ.

The mechanism of control of pulp vasculature, moreover, is still not well understood, although investigators are approaching the problem from several different directions. Edwall (72) has suggested that tissue metabolites, e.g., toxins, induce a negative feedback situation to increase pulpal microcirculation in inflammed areas by acting on alpha receptors located in the walls of the pulpal vasculature. It is known the vessels of the pulp organ have a minimal muscular coat (Han and Avery, '63; Corpron et al., '74), but the vessels of the pulp have a number of perivascular-associated cells that may be effected to function in vascular tone. In fact, a number of the labeled endings were found adjacent to these cells. Other substances have been suggested for the control of pulp vasculature, such as substance P (Olgart, '74), 5-hydroxytryptamine (Anderson and Naylor, '62), and prostaglandins (Bender, '78).

The surprising observation in this study was the large number of adrenergic endings in the odontogenic zone. Few blood vessels larger than precapillaries are found in this peripheral zone of the pulp. The adrenergic terminals found in this study were scattered throughout this zone, with the majority near the basal (proximal) ends of the odontoblasts. This observation does confirm, however, our earlier finding of adrenergic endings in the odontogenic zone (Avery, '75; Avery and Cox, '77) utilizing permanganate-fixed tissue. The functional significance of these terminals may be considered from several aspects. Wurtman and Axelrod ('66) have shown that a 24-hour variation in catecholamines occurs in peripheral adrenergic neurons in rat submandibular glands. Variations in adrenergic activity could indirectly induce changes in dentinogenesis through blood vascular changes or modulation of odontoblast metabolism. The resultant incremental pattern of the dentin would reflect these changes in blood flow and odontoblastic activity.

The free adrenergic endings found in this study suggest that adrenergic endings could have a role in the modulation of the efferent component of pain as proposed by Kroeger ('68). This hypothesis has been furthered by Edwall ('72), who found that the sensory nerve ending excitability could be modulated by varying pulpal blood flow. He further suggested that the frequency of the afferent impulses of intradentinal receptors may be modulated by the stimulation of sympathetic vasoconstrictor fibers. Matthews ('76) has also shown that sympathetic alpha receptors influence the facilitation of sensory units by approximately 30 times. Linnik-Kabat ('72) and Leranth and Czanyi ('67) have also suggested that pain from dentin could be modulated by the sympathetic adrenergic fibers interdigitating within the odontoblastic layer of the pulp.

Recent observations by Chiego et al. ('80) on the possible presence of horseradish peroxidase in the otic ganglion after injection into monkey teeth pulps infers that a parasympathetic influence may also be present in the pulp. The possibility of a sympathetic-parasympathetic relationship in the pulp would be of interest, especially when viewed in light of histochemical evidence of acetylcholinesterases in the pulp (Pohto and Antila, '68), quantitatively in pulp organs by Avery et al. ('71), in the subodontoblastic layer and nucleus of the odontoblast by Paulin and Vidmar ('79) see text, page 12, and The Periodontal Ligament by Mahan and Anderson ('71).

\section{ACKNOWLEDGMENTS}

We acknowledge the helpful assistance of Anthony A. Tomaro throughout the study.

\section{LITERATURE CITED}

Anderson, D.J., and M.N. Naylor (1962) Chemical excitants 
of pain in human dentine and dental pulp. Arch. Oral. Biol., 7:413-415.

Anneroth, G., and K.A. Norberg (1968) Adrenergic vasoconstrictor innervation in the human dental pulp. Acta Odont. Scand., 26:89-93.

Arwill, T. (1967) Studies on the ultrastructure of dental tissue. II. The predentine-pulpal border zone. Odont. Rev., 18:191-208.

Arwill, T., L. Edwall, J. Lilja, L. Olgant, and S.E. Svensson (1973) Ultrastructure of nerves in the dentinal-pulp border zone after sensory and autonomic nerve transection in the cat. Acta. Odont. Scand., 31:273-281.

Avery, J.K. (1975) Response of the pulp and dentin to contact with filling materials. J. Dent. Res., 54: Special Issue $B: B 188--197$.

Avery, J.K. (1979) Mechanism of reparative dentin formation and pain. In: Mechanism and Control of Pain, Louis I. Grossman, ed., Transactions of the Sixth International Conference on Endodontics. Masson Publishing USA, Inc., New York.

Avery, J.K., D.S. Strachan, R.E. Corpron, and C.F. Cox (1971) Morphological studies of the altered pulps of the New Zealand white rabbit after resection of the inferior alveolar nerve and/or the superior cervical ganglion. Anat. Rec., 171:495-508.

Avery, J.K., and C.F. Cox (1977) Role of nerves in teeth relative to pain and dentinogenesis in the trigeminal region. D.J. Anderson and B. Matthews, eds. Elsevier/ North Holland, Biomed. Press, pp. 37-48.

Bender, I.B. (1978) Pulp Biology Conference: A Discussion. J. Endo, 4:37-52.

Bodian, D. (1966) Herring bodies and neuroapocrine secretion in the monkey. An electron microscopic study of the fate of the neurosecretory product. Johns Hopkins Hospital Bulletin, 119(6):282-326.

Chiba, T. (1973) Electron microscopic and histochemical studies on the synaptic vesicles in mouse vas deferens and atrium after 5-hydroxydopamine administration. Anat. Rec., 176:35-48.

Chiego, D.J., Jr., C.F. Cox, and J.K. Avery (1980) H H HRP analysis of the nerve supply to primate teeth. J. Dent. Res., 59:736-744.

Corpron, R.E., J.K. Avery, and C.F. Cox (1972) Ultrastructure of intradentinal nerves after resection of the inferior alveolar nerve in mice. J. Dent. Res., 51:673.

Corpron, R.E., and J.K. Avery (1973) The ultrastructure of intradentinal nerves in developing mouse molars. Anat. Rec., 175:585-606.

Corpron, R.E., J.K. Avery, and Soo D. Lee (1974) Ultrastructure of terminal pulpal blood vessels in mouse molars. Anat. Rec., 179:527-540.

Cox, C.F., D.J. Chiego, Jr., J.K. Avery, and B.E. Bradley (1977) Horseradish Peroxidase Transport from Primate Dental Pulps. J. Dent. Res., 56:1184.

Edwall, L. (1972) Nervous control of blood circulation in dental pulp and the periodontal tissues. In: Oral Physi$\operatorname{olog} y$, N. Emmelin and Y. Zotterman, eds. Pergamon, New York, pp. 139-144.

Falk, B., N.A. Hillarp, G. Thieme, and A. Torp (1962) Fluorescence of catecholamines and related compounds condensed with formaldehyde. J. Histochem. Cytochem., 10:348-354.

Feher, E., K. Csanyi, and J. Vajda (1977) Ultrastructure and degeneration analysis of the never fibers of the tooth pulp in the cat. Arch. Oral Biol., 22:699-704.

Frank, R.M. (1968a) The ultrastructural relationship between the odontoblast, its process and the nerve fiber. In: Dentin and Pulp: Their structure and relations, N.B.B. Symons, ed. Livingston, London, pp. 115-145.

Frank, R.M. (1968b) Attachment sites between the odontoblast process and the intradentinal nerve fiber. Arch.
Oral Biol., 13:833-834.

Fullmer, H.M. (1959) The peracetic-orcein-Halmi stain: a stain for connective tissues. Stain Technol., 34:81-84.

Han, S.S., and J.K. Avery (1963) The ultrastructure of capillaries and arterioles of hamster dental pulp. Anat. Rec., 145:549-572.

Hand, A.R. (1972) Adrenergic and cholinergic nerve terminals in the rat parotid gland. Electron microscopic observations on permanganate-fixed glands. Anat. Rec., 173: $131-140$.

Hökfelt, T., and G. Johnsson (1968) Studies on reaction and binding of monamines after fixation and processing for electron microscopy with special reference to fixation with potassium permanganate. Histochemie., 16:45-67.

Ibata, Y., T. Matsuura, Y. Nojyo, T. Inoe, and Y. Sano (1974) The effect of 5-and 6-hydroxydopamine on the central monoaminergic neurons of the rat and the cat: fluorescence histochemistry and electron microscopy. Acta Histochem. Cytochem. 7(2):126-139.

Johansen, E. (1967) Ultrastructure of dentin. In: Structure and chemical organization of teeth. Vol. II, A.E.W. Miles, ed. New York Academic Press, pp. 35-74.

Kroeger, D.C. (1968) Possible role of neurohumoral substances in the pulp. In: Biology of the dental pulp, S.B. Finn, ed. University Alabama Press, pp. 333-352.

Larsson, P.A., and A. Linde (1971) Adrenergic vessel innervation in the rat incisor pulp. Scand. J. Dent. Res., 79:7-12.

Leranth, C., and K. Czanyi (1967) Innervation of teeth. Acta Morphologica Acad. Sci. Lung, 15:391-399.

Linnik-Kabat, A. (1972) Bole W. zakresie twarzoczaszki spowodowane zaburzeniami wegetatywnymi. Czas Stomat., 25:949-955.

Mahan, P.E., and K.V. Anderson (1971) Interaction of tooth pulp and periodontal ligament receptors in the dog and monkey. Exp. Neurol. 33(2): 441 443 .

Matthews, B. (1976) Effects of sympathetic stimulation on the response of intradental nerves to chemieal stimulation of dentin. In: Advances in pain research and therapy, Vol. I, J.J. Bonico and D.A. Fessard, eds. Raven Press, New York, pp. 195-203.

Mazzuca, M., and P. Poulain (1971) Neurophysiologie-Mise en evidence en microscopie electran-ique des terminaisons nerveuses monoaminergiques das l' eminence mediane du cobaye a l' aide de la 5-hydroxydopamine. Academie Des Sciences Comptes Rendus C.R. Acad. Sci. Paris, 273:1044-1047.

Nakano, G., H. Kuzuya, and T. Nagatsu (1970) Catecholamines in the dental pulp. J. Dent. Res., 49:(6) 1549.

Olgart, L. (1974) Excitation of intradentinal sensory units by pharmacological agents. Acta Physiol. Scand., 92:1-8.

Paulin, R., and V. Vidmar (1979) Cholinesterases and choline acetylase in isolated human and rat odontoblasts. Arch. Oral Biol., 24:217-223.

Pohto, P. (1972) Sympathetic adrenergic innervation of permanent teeth in the monkey (Macaca Irus). Acta Odont. Scand., 30: 117-126.

Pohto, R., and R. Antila (1968) Demonstration of adrenergic nerve fibers in human dental pulp by histochemical fluorescence method. Acta Odont. Scand., 26:137-144.

Pohto, P., R. Antila, and E. Klinge (1972) Quantitation of transmitter noradrenaline in the pulps of cat canine teeth. Proc. Finn. Dent. Soc., 68:20-25.

Prentice, F.D., and J.G. Wood (1974) Cytochemical localization of 5-hydroxydopamine in adrenergic elements of cat adrenal medulla. Experientia, 30(6):645-648.

Richards, J.G., and J.P. Tranzer (1970) The ultrastructural localization of amine storage sites in the central nervous system with the aid of a specific marker, 5-hydroxydopamine. Brain Res., 17:463-469.

Richardson, K.C. (1966) Electron microscopic identifica- 
tions of autonomic nerve endings. Nature, 210:756.

Sotelo, C. (1971) The fine structural localization of norepinephrine ${ }^{3} \mathrm{H}$ in the substantia nigra and area postrema of the rat: an autoradiographic study. J. Ultrastructural Res., 36:824-841.

'Tranzer, J.P., and H. Thoenen (1967) Electromicroscopic localization of 5-hydroxydopamine (3, 4, 5-trihydroxyphenyl-ethylamine), a new "false" sympathetic transmitter. Experientia, 23:743-745.

'Tranzer, J.P., H. Thoenen, R.L. Snipes, and J.G. Richards (1969) Recent developments on the ultrastructural aspect of adrenergic nerve endings in various experimental conditions. Progress in Brain Research-Mechanisms of Synaptic Transmission, 31:33-46.

Tsatsas, B.G., and R.M. Frank (1972) Ultrastructure of the dentinal tubular substances near the dentin-enamel junction. Calc. Tissue Res., 9:237-242.

Wurtman, R.J., and J. Axelrod (1966) A 24-hour rhythm in the content of norepinepherine in the pineal and salivary glands of the rat. Life Sci., 5:665-669.

Yax, G.L., C.F. Cox, and J.K. Avery (1977) Supplemental innervation of the mandibular mouse molar teeth. $J$ Dent. Res., 56:B163. A.A.D.R. Abst. 55, General Session, Las Vegas, p. 95. 